\title{
Effects of sinomenine on proliferation and apoptosis in human lung cancer cell line NCI-H460 in vitro
}

\author{
TINGSHU JIANG ${ }^{1 *}$, LIPING ZHOU ${ }^{*}$, WENLU ZHANG $^{3}$, DAN QU ${ }^{1}$, \\ XIAOMAN XU ${ }^{1}$, YING YANG ${ }^{4}$ and SHENGQI LI ${ }^{1}$

\begin{abstract}
${ }^{1}$ Department of Respiratory Medicine, The Shengjing Hospital of China Medical University; Departments of ${ }^{2}$ Laboratory Medicine, and ${ }^{3}$ Cardiology Medical, The First Hospital of China Medical University; ${ }^{4}$ Department of Oncology, The First Affiliated Hospital of Liaoning Medical University, Shenyang, Liaoning 110001, P.R. China
\end{abstract}

Received September 3, 2009; Accepted September 28, 2009

DOI: 10.3892/mmr_00000217

\begin{abstract}
Sinomenine (SIN) is an herbal ingredient isolated from Sinomenium acutum Rehd. et Wils. We evaluated the effects of SIN on the growth and apoptosis of human lung cancer NCI-H460 cells. SIN inhibited the proliferation of the cells in a dose- and time-dependent manner. Apoptosis was confirmed by flow cytometry, the TUNEL assay and transmission electron microscopy. SIN-induced apoptosis was accompanied by the collapse of mitochondrial membrane potential, the release of cytochrome $\mathrm{C}$ and the activation of caspase-9 and -3. SIN also increased Bax and decreased Bcl-2 protein levels in the NCI-H460 cells. Data analysis suggested that SIN exerted a significant apoptotic effect on NCI-H460 cells through the mitochondrial pathway. SIN is therefore a promising chemopreventive candidate for lung carcinoma.
\end{abstract}

\section{Introduction}

Lung cancer is the leading cause of cancer mortality in the United States (1) and worldwide in men and women. Although multimodality therapies and some molecular-targeted therapies have been applied, the clinical response to chemotherapy of patients with lung cancer is as yet unsatisfactory, and in many countries the 5 -year overall survival rate is less than $15 \%$ (2). To improve this rate, more effective chemopreventive and therapeutic approaches are required.

Sinomenine (7,8-didehydro-4-hydroxyl-3,7-dimethoxy-17methylmorphinan-6-one; SIN) (Fig. 1) is a principal alkaloid isolated from the stem and root of the Chinese medicinal plant Sinomenium acutum Rehd. et Wils (family Menispermaceae), which has been successfully used in Chinese folk medicine

Correspondence to: Dr Shengqi Li, Department of Respiratory Medicine, the Shengjing Hospital of China Medical University, No. 36, Sanhao Street, Shenyang, Liaoning 110001, P.R. China

E-mail: fengqiaoyebo@163.com

*Contributed equally

Key words: sinomenine, apoptosis, NCI-H460 lung cancer cell line for centuries to treat various autoimmune diseases (3). For pharmaceutical purposes, the hydrochloride chemical form of SIN is generally used. Previous reports have demonstrated that SIN has a wide range of pharmacological actions, including anti-inflammatory (4), antirheumatic $(5,6)$, analgesic $(7,8)$, antiarrhythmic (9), anti-angiogenesis (10), anti-lipidperoxidative $(4,11)$ and immunosuppressive effects $(12)$. In a few studies, SIN has also been reported to have an antitumor effect $(13,14)$.

Apoptosis, or programmed cell death, is defined as an active physiological process of cell self-destruction involving specific morphological and biochemical changes. Certain agents are capable of suppressing the proliferation of malignant cells by inducing apoptosis. The mechanism of apoptosis mainly involves the mitochondrial, endoplasmic-reticulumspecific and cell death receptor signaling pathways. The key element in the mitochondrial pathway is the efflux of cytochrome $\mathrm{C}$ from mitochondria to the cytosol. Once there, it forms a complex (apoptosome) with Apaf-1 and caspase-9, leading to the activation of caspase-3 (15). The cell death receptor pathway is characterized by the binding of cell death ligands and receptors, with the subsequent activation of caspase- 8 and -3 (16). The endoplasmic reticulum pathway is characterized by the activation of caspase-12 (17).

In the present study, we evaluated the effects of SIN on the growth of the human lung cancer cell line NCI-H460, and investigated the mechanisms involved in SIN-induced apoptosis.

\section{Materials and methods}

Materials and chemicals. Cell culture media RPMI-1640, antibiotics and trypsin were obtained from Biological Industries (Kibutz Beit Haemek, Israel). Fetal bovine serum (FBS) was purchased from Beijing Solarbio Science \& Technology Co., Ltd. (China). 3-(4,5-dimethyl thiazol-2yl)-2, 5-diphenyltetrazolium bromide (MTT) and dimethyl sulfoxide (DMSO) were purchased from Sigma-Aldrich (St. Louis, MO, USA). Annexin V-FITC and propidium iodide (PI) double staining kit, fluorescent dye rhodamine 123 and the terminal transferase-mediated dUTP nick-end-labeling (TUNEL) assay were purchased from Key Gene (Nanjing, 


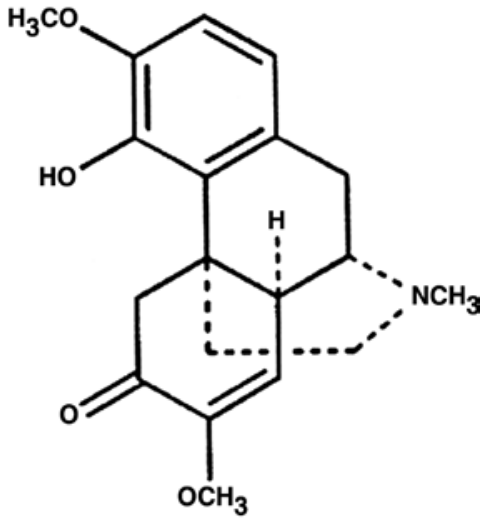

Figure 1.The structure of sinomenine.

China). Caspase-3 -8 and -9 Activity Assay kits were acquired from the Beyotime Institute of Biotechnology (Jiangsu, China). Sinomenine (HPLC purity 98\%) was purchased from Xi'an Sobeo Pharmtech Co., Ltd. (Xi'an, China). A 2-mM stock solution of SIN was prepared in RPMI-1640 growth medium and stored at $-20^{\circ} \mathrm{C}$. The Mitochondria/Cytosol Fractionation Kit was purchased from BioVision (Mountain View, CA, USA). Antibodies against cytochrome C, Bcl-2 and Bax were purchased from Key Gene. Horseradish peroxidaseconjugated secondary antibody was obtained from Santa Cruz Biotechnology (Santa Cruz, CA, USA). Cisplatin (DDP) was purchased from QILU Pharmaceutical Co., Ltd. (Jinan, Shandong, China). All other chemicals were obtained from Sinopharm Chemical Reagent Co., Ltd. (Shenyang, China).

Cell culture. NCI-H460 cells derived from human lung cancer were obtained from the China Center for Type Culture Collection (Wuhan, China) and cultured in RPMI-1640 medium supplemented with $10 \%$ FBS, $100 \mathrm{U} / \mathrm{ml}$ penicillin and $100 \mathrm{mg} / \mathrm{ml}$ streptomycin. Cultures were maintained in a humidified incubator at $37^{\circ} \mathrm{C}$ in the presence of $5 \% \mathrm{CO}_{2}$. The culture medium was changed every 2 days. Cells for assay were detached by a solution of $0.125 \%$ trypsin and $0.02 \%$ EDTA.

MTT assay. The effect of SIN on in vitro NCI-H460 cell proliferation was determined by measuring the MTT dye absorbance of living cells. In brief, cells $\left(1 \times 10^{4}\right.$ cells/well) were seeded in 96-well tissue culture plates, and then cultured in RPMI-1640 growth medium for $24 \mathrm{~h}$. Subsequently, the medium was replaced with RPMI-1640 growth medium containing designated concentrations of SIN (20,40, 80, 120, 160 and $200 \mu \mathrm{g} / \mathrm{ml})$ and, as positive control, DDP (3 $\mu \mathrm{g} /$ $\mathrm{ml})$. After exposure to SIN or DDP for 24,48 or $72 \mathrm{~h}, 25 \mu \mathrm{l}$ of MTT solution ( $2 \mathrm{mg} / \mathrm{ml}$ in PBS) was added to each well, and the plates were incubated for an additional $4 \mathrm{~h}$ at $37^{\circ} \mathrm{C}$. MTT solution in the medium was aspirated off and $150 \mu \mathrm{l}$ of DMSO was added to each well to solubilize the formazan crystals formed in viable cells. Optical density was measured at $570 \mathrm{~nm}$ using an ELISA plate reader (Model 550; Bio-Rad, USA). Each plate contained multiple wells for a given experimental condition and multiple control wells. The procedure was replicated three times.
Annexin VIPI flow cytometric analysis. The amount of phosphatidylserine exposed on the outside of the apoptotic cells was determined by an Annexin V-FITC Apoptosis Kit. Briefly, following treatment with SIN (120 and $200 \mu \mathrm{g} / \mathrm{ml}$ ) for $48 \mathrm{~h}$, $1 \times 10^{6}$ cells were harvested by centrifugation $(1,000 \mathrm{rpm} / \mathrm{min})$, washed twice with ice-cold PBS, pelleted and resuspended in $100 \mu \mathrm{l}$ Annexin V-FITC/PI binding buffer. Following the addition of $5 \mu \mathrm{l}$ Annexin V-FITC conjugate and $10 \mu \mathrm{l}$ PI buffer, the cells were incubated at room temperature for $15 \mathrm{~min}$ in the dark. Annexin V-FITC binding buffer (300 $\mu \mathrm{l})$ was then added, and the cells were analyzed using a FACScan flow cytometer with Cell Quest software (Becton Dickinson, San Jose, CA, USA). Positive cells were incubated with DDP $(3 \mu \mathrm{g} / \mathrm{ml})$ and control cells were treated with medium only.

Morphological analysis of apoptosis by TUNEL staining and transmission electron microscopy. Cell morphology was evaluated by TUNEL staining. Briefly, cells were cultured in medium containing $10 \%$ FBS in the presence of 120 and $200 \mu \mathrm{g} / \mathrm{ml} \mathrm{SIN}$. Following $48 \mathrm{~h}$ of incubation, the cells were harvested and smeared on glass slides. After fixation with $4 \%$ paraformaldehyde, the cells were permeabilized in PBS containing $0.1 \%$ Triton X-100 for 2 min on ice. Cell death was detected by the TUNEL assay using the In Situ Cell Death Detection Kit. Briefly, slides were treated with reagent mixture and incubated in a humidified atmosphere for $60 \mathrm{~min}$ at $37^{\circ} \mathrm{C}$ in the dark, and then visualized on a microscope. Fixed and permeabilized cells treated with DNase I (300 U) were used as positive controls for TUNEL staining. Medium alone was used as a control.

Apoptosis was observed using transmission electron microscopy (TEM). Briefly, cells treated with $200 \mu \mathrm{g} / \mathrm{ml} \mathrm{SIN}$ for $48 \mathrm{~h}$ were harvested and fixed in $3 \%$ glutaraldehyde for $1 \mathrm{~h}$. After removal of the primary fixative, cells were washed three times with MOPS buffer, post-fixed in $1 \%$ osmium tetroxide $\left(\mathrm{OsO}_{4}\right)$, dehydrated in graded alcohol and embedded in epoxy resin. Ultra thin sections were double-stained with lead citrate/ uranyl acetate prior to examination using a JEM-100CX transmission electron microscope (Japan).

Quantification of caspase-3, -8 and -9 activity. Caspase activity was measured using the Caspase Activity Assay according to the manufacturer's instructions. Briefly, $1 \times 10^{6}$ cells were incubated with designated concentrations of SIN (120 and $200 \mu \mathrm{g} / \mathrm{ml})$ for $24 \mathrm{~h}$. The cells were washed with ice-cold PBS, resuspended in lysis buffer and left on ice for $15 \mathrm{~min}$. The lysate was centrifuged at $12,000 \mathrm{rpm} / \mathrm{min}$ at $4^{\circ} \mathrm{C}$ for $15 \mathrm{~min}$. The activity of caspase-3, -8 and -9 was measured using the substrate peptides Ac-DEVD-p-nitroanilide (pNA), Ac-IETD-pNA and Ac-LEHD-pNA, respectively. The release of pNA was qualified by determining absorbance with the Multiskan Spectrum spectrophotometer (Thermo Scientific) at $405 \mathrm{~nm}$.

Measurement of mitochondrial membrane potential. Mitochondrial membrane potential $(\Delta \Psi \mathrm{m})$ was monitored using fluorescent dye rhodamine 123. Depolarization of $\Delta \Psi \mathrm{m}$ results in the loss of rhodamine 123 and a decrease in intracellular fluorescence. In brief, $1 \times 10^{6}$ cells were incubated with the designated concentrations of SIN (120 and $200 \mu \mathrm{g} / \mathrm{ml}$ ) 
for $48 \mathrm{~h}$. Cells were washed twice with PBS and incubated with rhodamine $123(1 \mu \mathrm{g} / \mathrm{ml})$ at $37^{\circ} \mathrm{C}$ for $30 \mathrm{~min}$. The cell count was measured using a FACStar flow cytometer and analyzed using ModFit software. Positive cells were incubated with DDP ( $3 \mu \mathrm{g} / \mathrm{ml}$ ) and control cells were treated with medium only.

Detection of cytochrome C release from mitochondria. After treatment with appropriate concentrations of SIN (80, 120, 160 and $200 \mu \mathrm{g} / \mathrm{ml}$ ) for $48 \mathrm{~h}, 3 \times 10^{7}$ cells were harvested and collected by centrifugation at $1000 \mathrm{rpm} / \mathrm{min}$ for $8 \mathrm{~min}$ at $4^{\circ} \mathrm{C}$. The cells were washed with $10 \mathrm{ml}$ of ice-cold PBS and were centrifuged again. The supernatant was removed and the cells were suspended with $1.0 \mathrm{ml}$ of Cytosol Extraction Buffer Mix containing DTT and protease inhibitors. The mixture was incubated on ice for $15 \mathrm{~min}$, then the cells were homogenized in an ice-cold tissue grinder for 40 passes. The homogenate was transferred to a $1.5-\mathrm{ml}$ tube and centrifuged at 1,000 rpm/ $\min$ for $10 \mathrm{~min}$ at $4^{\circ} \mathrm{C}$. The supernatant was carefully collected and centrifuged again at $12,000 \mathrm{rpm} / \mathrm{min}$ for $30 \mathrm{~min}$ at $4^{\circ} \mathrm{C}$. This supernatant was used as the cytosolic fraction. The pellet was resuspended with $100 \mu \mathrm{l}$ of Mitochondrial Extraction Buffer Mix containing DTT and protease inhibitors. This sample was used as the mitochondrial fraction. The resultant products were visualized by Western blot analysis.

Western blot analysis of apoptosis-related proteins. The expression of apoptosis-related proteins was evaluated by Western blotting. In brief, $3 \times 10^{7}$ cells were incubated with the designated concentrations of SIN $(80,120,160$ and $200 \mu \mathrm{g} / \mathrm{ml})$ for $48 \mathrm{~h}$. The cells were then washed in PBS and suspended in five volumes of lysis buffer (20 mM HEPES, pH 7.9, $20 \%$ glycerol, $200 \mathrm{mM} \mathrm{KCl,} 0.5 \mathrm{mM}$ EDTA, 0.5\% NP40, $0.5 \mathrm{mM}$ DTT and $1 \%$ protease inhibitor cocktail). The lysates were collected and stored at $-20^{\circ} \mathrm{C}$ until further use. Supernatant protein concentration was determined by the Bradford method. Supernatant samples containing $40 \mu \mathrm{g}$ of total protein were resolved by SDS-PAGE gel depending on the target protein size, transferred to PVDF membranes by electroblotting and probed with anti-cytochrome $\mathrm{C}$, anti-Bax, anti-Bcl-2 and anti-Actin. Membranes were incubated with horseradish peroxidase-conjugated secondary antibodies. Blots were developed using an enhanced chemiluminescencence kit.

Statistical analysis. Experiments were conducted three times. The results were expressed as the mean \pm standard deviation and evaluated using one- or two-way analysis of variance (ANOVA) followed by the Student's t-test. Statistical significance was defined as $\mathrm{P}<0.05$.

\section{Results}

Inhibition of the proliferation of NCI-H460 cells by sinomenine. We first investigated the potential cell proliferation inhibition activity of SIN in lung cancer cells. As shown in Fig. 2, SIN inhibited cell proliferation in NCI-H460 cells in a concentration- and time-dependent manner. Maximal inhibition of proliferation was observed at $72 \mathrm{~h}$ with $200 \mu \mathrm{g} / \mathrm{ml}$ SIN, which inhibited proliferation in $85.89 \%$ of the NCI-H460 cells.

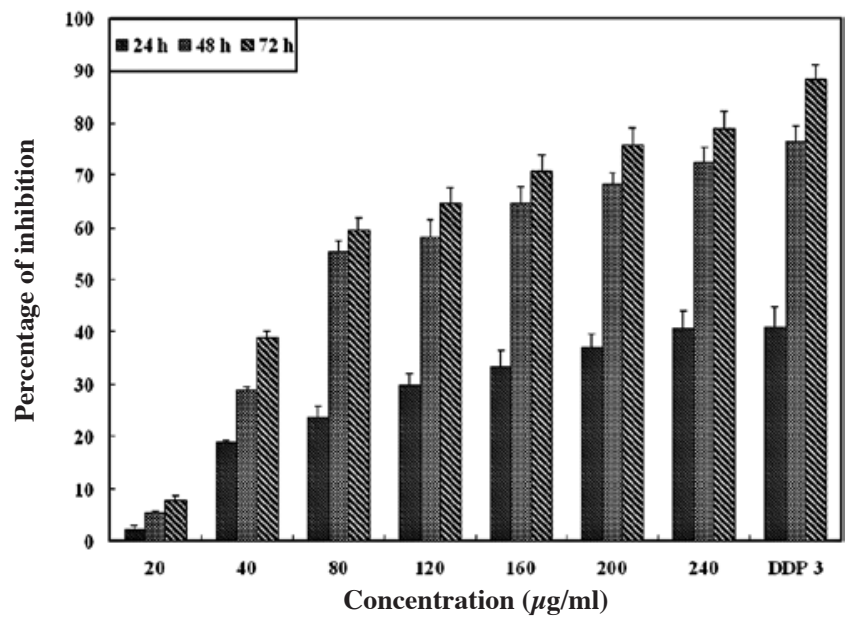

Figure 2.The effects of sinomenine on cell proliferation inhibition in the lung cancer cell line NCI-H460. DDP $(3 \mu \mathrm{g} / \mathrm{ml})$ was used as a positive control.

Induction of apoptosis in NCI-H460 cells by sinomenine. To further confirm the induction of apoptosis by SIN, cells were stained with Annexin V/PI. The TUNEL assay and TEM were simultaneously performed. As displayed in Fig. 3A and B, the proportion of Annexin V-positive cells in the SIN-treated cells increased in a dose-dependent manner, which supports the finding that SIN induced NCIH-460 cell death by apoptosis. As demonstrated in Fig. 3C, treatment with SIN (120 and $200 \mu \mathrm{g} / \mathrm{ml}$ ) for $48 \mathrm{~h}$ significantly induced apoptotic cell death. Cells exhibited condensed nuclei and there was an increase in cells positive for TUNEL staining, suggesting that DNA fragmentation had occurred. TEM revealed the various morphological alterations in the NCI-H460 cells after treatment with SIN $(200 \mu \mathrm{g} / \mathrm{ml})$ for $48 \mathrm{~h}$. As shown in Fig. 3D, chromatin condensation and nuclear fragmentation were observed in treated NCI-H460 cells. Apoptosis was also demonstrated in the DDP-treated $(3 \mu \mathrm{g} / \mathrm{ml})$ positive control cells by Annexin V/PI staining. For the TUNEL assay, DNase I (300 U) was used as a positive control.

Association of sinomenine-induced apoptosis with caspase-3 and -9 activation. To evaluate the molecular effectors of the apoptotic pathway involved in SIN-induced apoptosis, the activity of caspase-3, -8 and -9 was measured. As shown in Fig. 4, activation of caspase- 3 and -9 was significantly increased after SIN treatment for $24 \mathrm{~h}$, while no alteration of caspase-8 activity was observed in SIN-treated cells.

Mitochondrial pathway involvement in sinomenine-induced apoptosis. In order to further confirm mitochondrial involvement in SIN-induced apoptotic cell death, we examined disruption in the $\Delta \Psi \mathrm{m}$ and the release of cytochrome $\mathrm{C}$ from mitochondria into the cytoplasm. As demonstrated in Fig. 5A and B, as compared to controls, the proportion of depolarized cells among SIN-treated cells was increased in a dose-dependent manner. Cells were shifted towards the left when treated with 120 and $200 \mu \mathrm{g} / \mathrm{ml} \mathrm{SIN} \mathrm{for} 48 \mathrm{~h}$. The results indicate that SIN treatment induces significant disruption of $\Delta \Psi \mathrm{m}$. DDP $(3 \mu \mathrm{g} / \mathrm{ml})$ was applied for $48 \mathrm{~h}$ as a positive control. Western blot analysis revealed an increase 
A
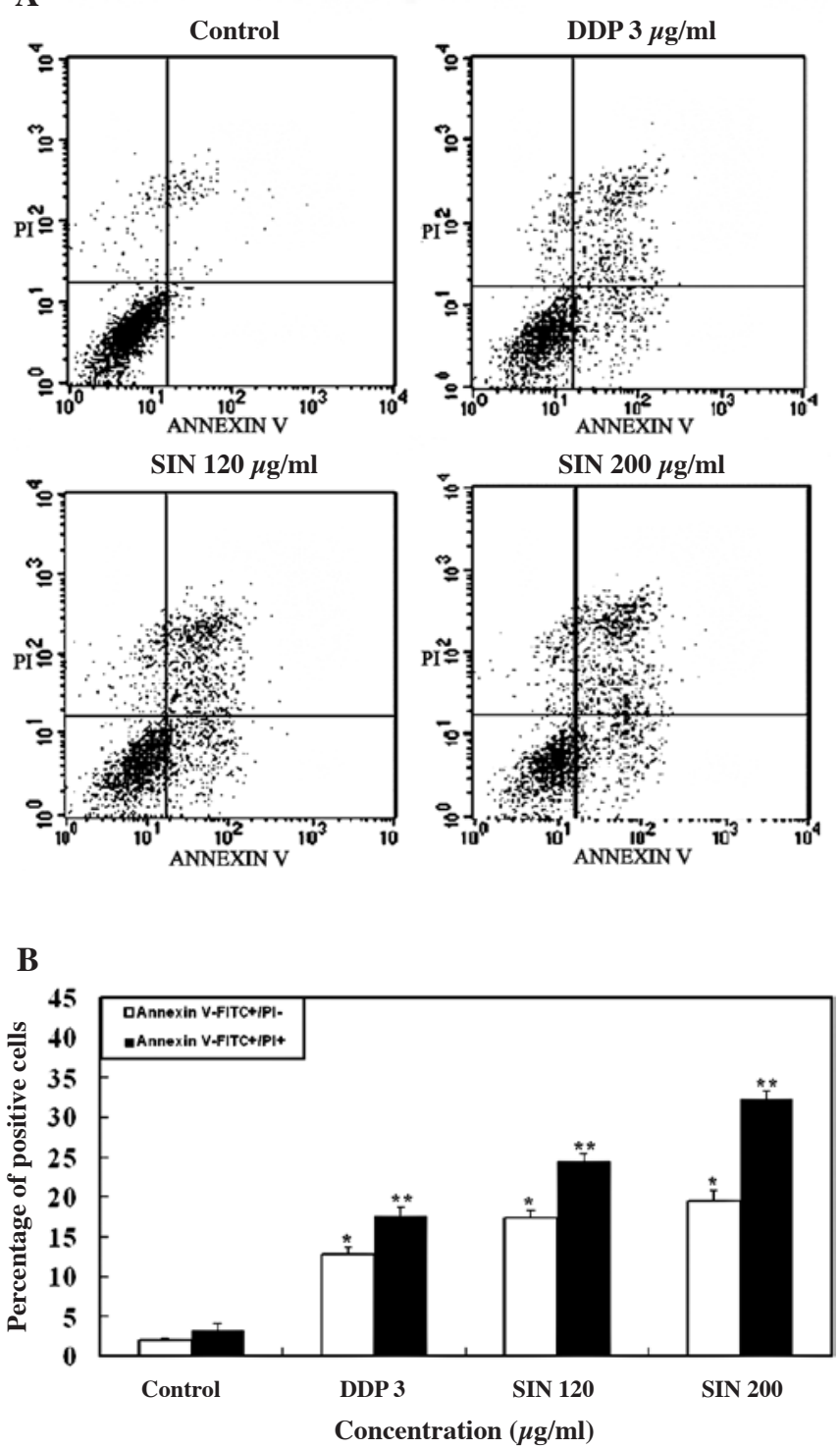

C

D

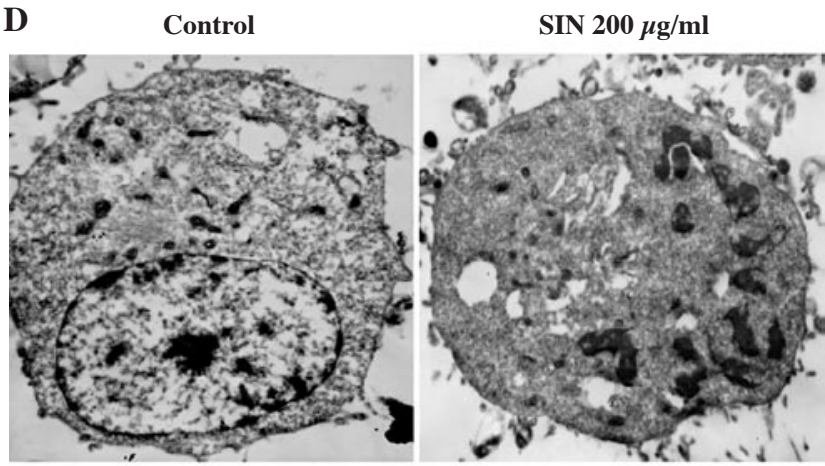

Ultrastructural analysis by TEM
DNase I $300 \mathrm{U}$

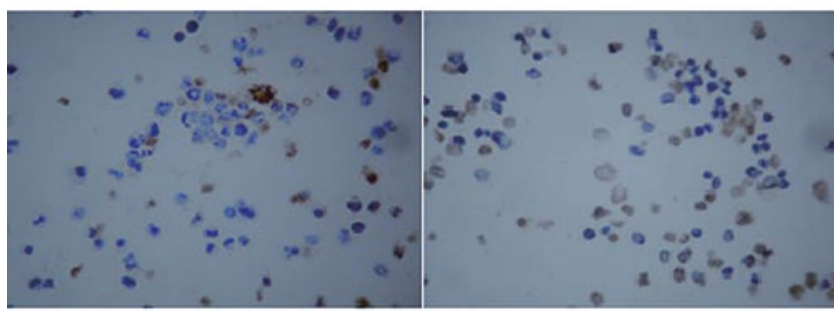

SIN $120 \mu \mathrm{g} / \mathrm{ml}$

$\operatorname{SIN} 200 \mu \mathrm{g} / \mathrm{ml}$

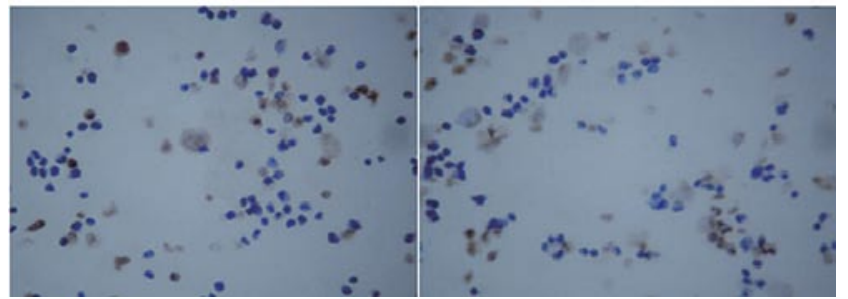

Figure 3. Induction of apoptosis by sinomenine. (A) NCI-H460 cells were treated with SIN (120 and $200 \mu \mathrm{g} / \mathrm{ml})$ or with DDP ( $3 \mu \mathrm{g} / \mathrm{ml}$ ) for $48 \mathrm{~h}$. The cells were then harvested and stained with Annexin V/PI, and flow cytometric analysis was performed to determine the extent of apoptosis. (B) Summary of the apoptosis data from the histograms. ${ }^{*}$ p $<0.05$ vs. the control group (Annexin V-positive); ${ }^{* *}$ p $<0.05$ vs. the control group (Annexin V and PI-positive). (C) NCI-H460 cells were treated with SIN (120 and $200 \mu \mathrm{g} / \mathrm{ml}$ ) or DNase I (300 U) for $48 \mathrm{~h}$; nuclei were characterized by the TUNEL assay and investigated under a microscope. Magnification x200. (D) Electron micrographs of NCI-H460 control cells and cells treated with SIN (200 $\mu \mathrm{g} / \mathrm{ml})$ for $48 \mathrm{~h}$. Magnification x8000; TEM.

in cytosolic cytochrome $\mathrm{C}$ after SIN treatment in NCI-H460 cells (Fig. 5C). The relative density of cytochrome $\mathrm{C}$ in the mitochondrial fraction was decreased for the SIN-treated fraction as compared to the control. These results suggest that cytochrome C release is involved in SIN-induced apoptosis.

Sinomenine-induced expression of apoptosis-related Bcl-2 family proteins. In order to gain a better understanding of the molecular basis of SIN-induced apoptosis, we investigated the expression levels of Bcl-2 and Bax by Western blot analysis. Western blotting showed that SIN treatment led to a decrease in Bcl-2 levels and an increase in Bax levels as compared to the control cells (Fig. 6A). The ratio of Bax/Bcl-2 increased in conjunction with an increase in the concentration of SIN. These results indicate that SIN up-regulates Bax protein expression and down-regulates Bcl-2 protein expression (Fig. 6B).

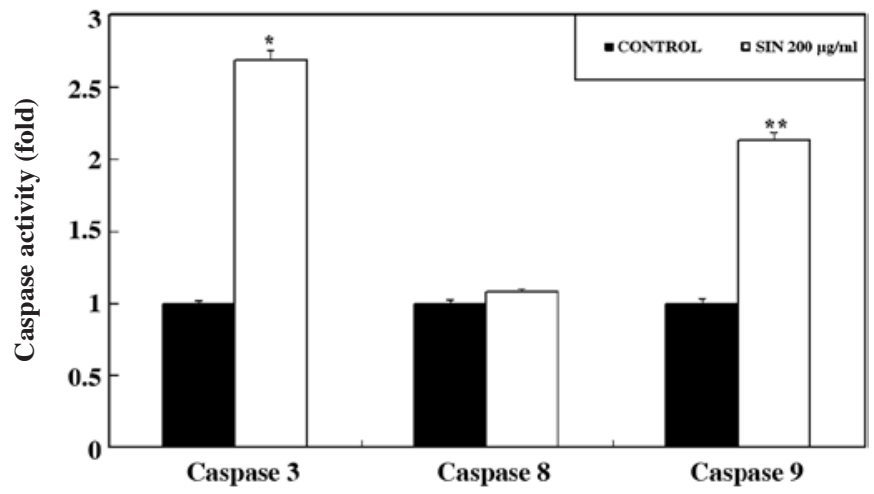

Figure 4. Effect of sinomenine (SIN) on the activity of caspase-3, -8 and -9 in SIN-induced apoptosis. NCI-H460 cells were treated with SIN $(200 \mu \mathrm{g} / \mathrm{ml})$ for 24 h. ${ }^{*} \mathrm{p}<0.05$ vs. the control group (caspase-3); ${ }^{* *} \mathrm{p}<0.05$ vs. the control group (caspase-9). 
A
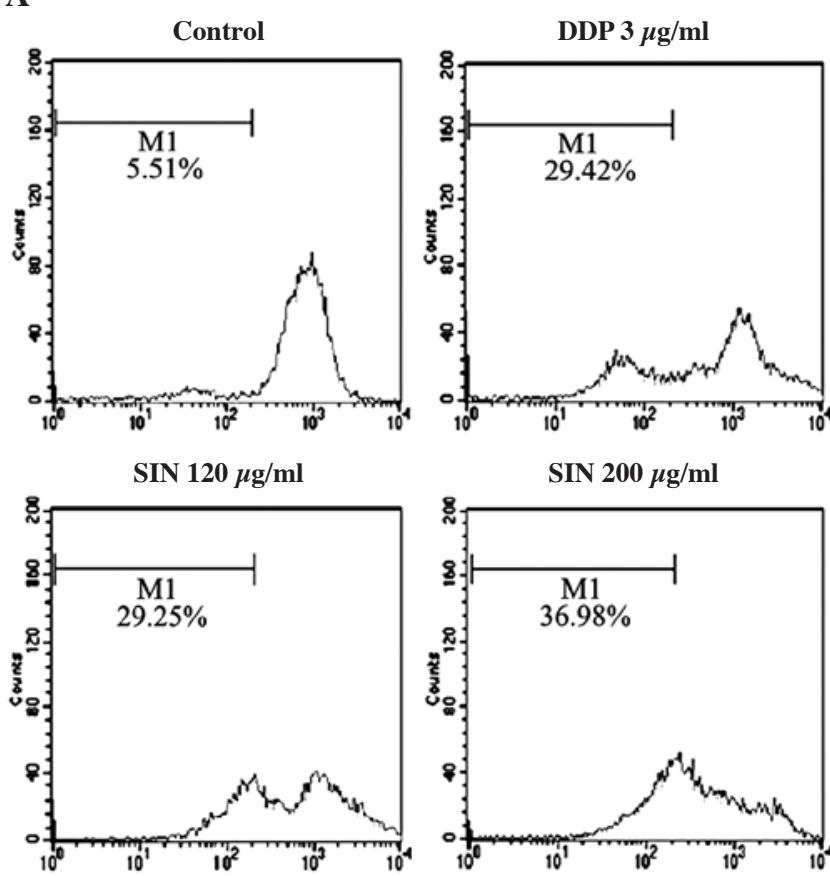

B

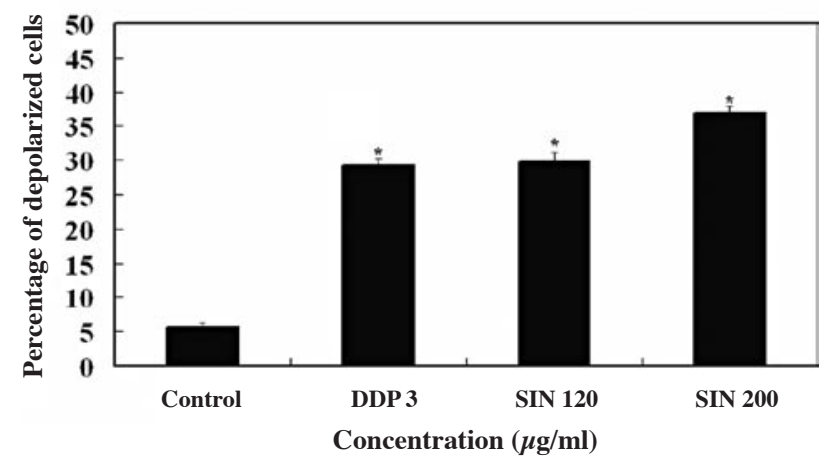

C

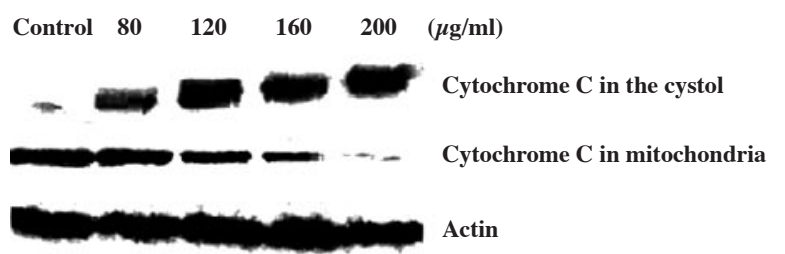

Figure 5. Sinomenine (SIN)-induced disruption of mitochondrial membrane potential $(\Delta \Psi \mathrm{m})$ and release of mitochondrial cytochrome C. (A) NCI-H460 cells were treated with SIN (120 and $200 \mu \mathrm{g} / \mathrm{ml})$ or DDP $(3 \mu \mathrm{g} / \mathrm{ml})$ for $48 \mathrm{~h}$. The cells were then harvested and stained with rhodamine 123, and flow cytometric analysis was performed to analyze $\Delta \Psi \mathrm{m}$. (B) Summary of the depolarization data from the histograms. " $\mathrm{p}<0.05$ vs. the control group. (C) NCI-H460 cells were treated with $\operatorname{SIN}(80,120,160$ and $200 \mu \mathrm{g} / \mathrm{ml})$ for $48 \mathrm{~h}$ After the mitochondrial and cytosolic fraction were isolated, mitochondrial cytochrome $\mathrm{C}$ release was detected by Western blot analysis.

\section{Discussion}

Lung cancer is the leading cause of cancer mortality in the United States and worldwide. The two major forms of lung cancer are non-small cell lung cancer $(\sim 85 \%$ of all lung
A

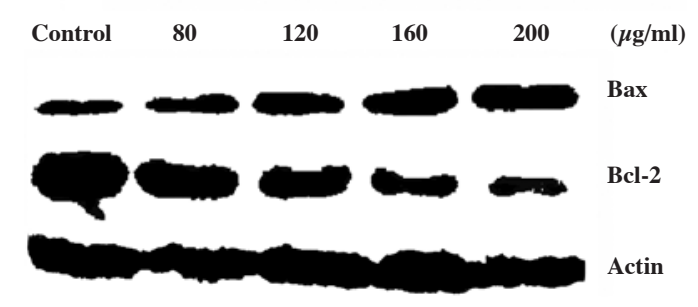

B

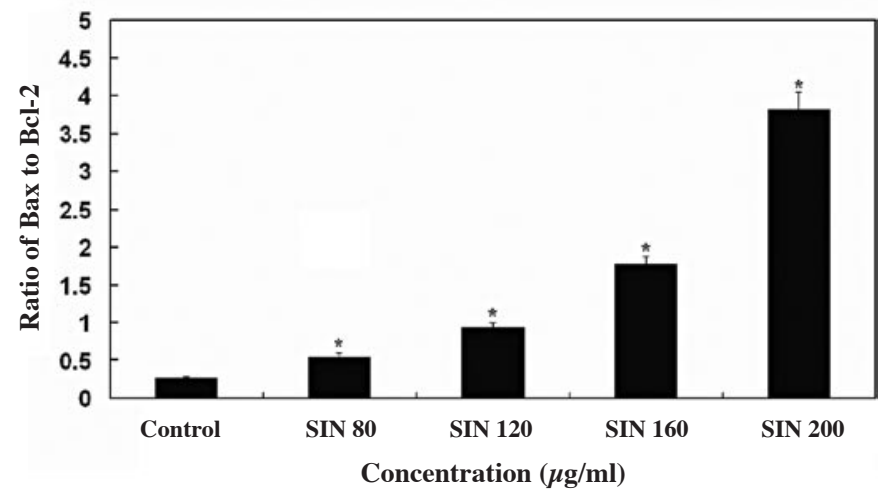

Figure 6. Effect of sinomenine (SIN) on the expression of apoptosis-related proteins in NCI-H460 cells. (A) NCI-H460 cells were treated with SIN (80, 120,160 and $200 \mu \mathrm{g} / \mathrm{ml}$ ) for $48 \mathrm{~h}$. Total cell lysates were prepared and Western blot analysis was performed using antibodies against Bax, Bcl-2 and actin. (B) The ratio of Bax/Bcl-2 was demonstrated by histograms. " $\mathrm{p}<0.05$ vs. the control group.

cancer cases) and small-cell lung cancer ( $\sim 15 \%$ of cases). Despite advances in early detection and the development of standard treatment, non-small cell lung cancer is often diagnosed at an advanced stage and has a poor prognosis (18). The need for new chemopreventive and antitumor agents remains a key issue facing clinical practice. Several studies have demonstrated that extracts from Chinese medicinal herbs have anticancer potential, and such herbs have been receiving increasing attention.

SIN, a pure alkaloid extracted from the Chinese medicinal plant Sinomenium acutum Rehd. et Wils, has been used for centuries in the treatment of patients with various rheumatoid diseases in China. In this study, SIN inhibited the proliferation of cells by inducing apoptosis in a time- and concentrationdependent manner. At lower concentrations $(<80 \mu \mathrm{g} / \mathrm{ml})$, SIN did not exhibit a significant inhibitory effect. However, at higher concentrations $(>200 \mu \mathrm{g} / \mathrm{ml})$, SIN resulted in marked necrosis. Consequently, we evaluated the effects of SIN on the apoptosis of NCI-H460 cells at concentrations of 120 and $200 \mu \mathrm{g} / \mathrm{ml}$ ). The apoptosis induced by SIN was confirmed by three methods.

Apoptosis is a controlled type of cell death characterized by cell shrinkage, membrane blebbing and DNA fragmentation. Mitochondria are thought to play a pivotal role in apoptosis. The mitochondrial apoptotic pathway has been described as an important signaling pathway of apoptosis (19-21). Anti-cancer agents extracted from Chinese herbs have been shown to induce the apoptosis of cancer cells through the mitochondrial apoptotic pathway $(22,23)$. 
In the present study, the loss of $\Delta \Psi \mathrm{m}$ and the release of cytochrome C were observed in SIN-treated NCI-H460 cells. Furthermore, SIN induced apoptosis by increasing the activation of caspase- 3 and -9 activities. Therefore, the mitochondrial pathway was involved in SIN-induced apoptosis. The mitochondrial apoptotic pathway of cell death is regulated by the Bcl-2 family proteins, which can be subdivided into anti-apoptotic (e.g., Bcl-2, Bcl-XL and Mcl-1) and pro-apoptotic (e.g., Bax, Bad, Bak, Bcl-Xs and NOXA) members (24). The balance between the pro-apoptotic and pro-survival Bcl-2 family members determines whether the cell survives or undergoes apoptosis (25). Decreases in the expression of pro-apoptotic Bcl-2 proteins or overexpression of anti-apoptotic Bcl-2 proteins is associated with enhanced oncogeneic potential and resistance to chemotherapy, respectively (26). Following treatment of NCI-H460 cells with SIN, a significant increase in Bax expression and a decrease of Bcl-2 was observed, suggesting that changes in the ratio of pro- to anti-apoptotic Bcl-2 family of proteins might contribute to the promotion of the apoptotic activity of SIN. These occurrences of mitochondrial apoptotic events are correlated with the effect of SIN on Bcl-2 family proteins, confirming that SIN-induced apoptosis is associated with the regulation of the Bcl-2 family of proteins.

In conclusion, this is the first report indicating that SIN has a cytotoxic effect on human lung cancer cells (NCI-H460 cell line) and is also the first study on the molecular mechanisms behind its anticancer activity. SIN has significant potential as an anti-cancer agent. However, future in vivo animal studies are necessary to determine its therapeutic efficacy in the treatment of non-small cell lung cancer.

\section{References}

1. Jemal A, Siegel R, Ward E, Murray T, Xu J and Thun M: Cancer statistics, 2008. CA Cancer J Clin 58: 71-96, 2008.

2. Erridge S, Moller H, Price A and Brewster D: International comparisons of survival from lung cancer: pitfalls and warnings. Nat Clin Pract Oncol 4: 570-577, 2007.

3. Yamasaki H: Pharmacology of sinomenine, an anti-rheumatic alkaloid from Sinomenium acutum. Acta Med Okayama 30: 1-20, 1976.

4. Qian L, Xu Z, Zhang W, Wilson B, Hong JS and Flood PM: Sinomenine, a natural dextrorotatory morphinan analog, is anti-inflammatory and neuroprotective through inhibition of microglial NADPH oxidase. J Neuroinflammation 4: 23-37, 2007.
5. Liu L, Buchner E, Beitze D, et al: Amelioration of rat experimental arthritides by treatment with the alkaloid sinomenine. Int J Immunopharmacol 18: 529-543, 1996.

6. Zhou H, Wong Y, Wang J, Cai X and Liu L: Sinomenine ameliorates arthritis via MMPs, TIMPs and cytokines in rats. Biochem Biophys Res Commun 376: 352-357, 2008.

7. Wang M, Chang C, Cheng J, Wu H, Li Y and Cheng J: Activation of opioid mu-receptor by sinomenine in cell and mice. Neurosci Lett 443: 209-212, 2008.

8. Xu S, Shen X, Li Z, Wu B and Jang C: On the mechanism of sinomenine 'analgesia'. Sheng Li Xue Bao 27: 281-291, 1964.

9. Zhao D, Yang X, Li Z and Sheng B: Antiarrhythmic effects of sinomenine hydrochloride. Yao Xue Xue Bao 20: 856-858, 1985.

10. Kok T, Yue P, Mak N, Fan T, Liu L and Wong R: The antiangiogenic effect of sinomenine. Angiogenesis 8: 3-12, 2005.

11. Li L, Gao X and Ding B: Inhibitory effect of sinomenine on $\mathrm{H} 2 \mathrm{O} 2$-induced apoptosis in neonatal rat cardiomyocytes. Zhongguo Zhong Yao Za Zhi 33: 939-941, 2008.

12. He X, Wang J, Guo Z, et al: Requirement for ERK activation in sinomenine-induced apoptosis of macrophages. Immunol Lett 98: 91-96, 2005.

13. Li X, Yue P, Ha W, et al: Effect of sinomenine on gene expression of the IL-1 beta-activated human synovial sarcoma. Life Sci 79: 665-673, 2006.

14. Gong L and Gao Y: Apoptotic derivation of hepatoma carcinoma cell by kukoline. J Chengdu Univ Tradit Chin Med 30: 38-39, 2007.

15. Mehmet H: Caspases find a new place to hide. Nature 403: 29-30, 2000.

16. De Maria R, Lenti L, Malisan F, et al: Requirement for GD3 ganglioside in CD95 and ceramide-induced apoptosis. Science 277: 1652-1655, 1997.

17. Nakagawa T, Zhu H, Morishima N, et al: Caspase-12 mediates endoplasmic-reticulum-specific apoptosis and cytotoxicity by amyloid beta. Nature 403: 98-103, 2000.

18. Herbst R, Heymach J and Lippman S: Lung cancer. N Engl J Med 359: 1367-1380, 2008.

19. Kasibhatla S and Tseng B: Why target apoptosis in cancer treatment? Mol Cancer Ther 2: 573-580, 2003.

20. Waxman D and Schwartz P: Harnessing apoptosis for improved anticancer gene therapy. Cancer Res 63: 8563-8572, 2003.

21. Hengartner M: The biochemistry of apoptosis. Nature 407: 770-776, 2000.

22. Hsu H, Houng J, Kuo C, Tsao N and Wu Y: Glossogin, a novel phenylpropanoid from Glossogyne tenuifolia, induced apoptosis in A549 lung cancer cells. Food Chem Toxicol 46: 3785-3791, 2008.

23. Magesh V, Lee J, Ahn K, et al: Ocimum sanctum induces apoptosis in A549 lung cancer cells and suppresses the in vivo growth of lewis lung carcinoma cells. Phytother Res: Mar, 2009 (E-pub ahead of print).

24. Certo M, Del Gaizo Moore V, Nishino M, et al: Mitochondria primed by death signals determine cellular addiction to antiapoptotic BCL-2 family members. Cancer Cell 9: 328-330, 2006.

25. Lanave C, Santamaria M and Saccone C: Comparative genomics: the evolutionary history of the Bcl-2 family. Gene 333: 71-79, 2004.

26. Papadopoulos K: Targeting the Bcl-2 family in cancer therapy. Semin Oncol 33: 449-456, 2006. 